\title{
School performance and hospital admission due to unipolar depression: a three-generational study of social causation and social selection
}

Ulf Jonsson $^{1,2}$, Anna Goodman ${ }^{3,4}$, Anne-Liis von Knorring ${ }^{1}$, Lars von Knorring ${ }^{2}$ and Ilona Koupil ${ }^{4}$

1 Department of Neuroscience, Child and Adolescent Psychiatry, Uppsala University, Uppsala, SE-751 85 Sweden

2 Department of Neuroscience, Psychiatry, Uppsala University, Uppsala, SE-751 85 Sweden

3 Faculty of Epidemiology and Population Health, London School of Hygiene and Tropical Medicine, London, UK

$4 \quad$ Centre for Health Equity Studies (CHESS), Stockholm University/Karolinska Institutet, Stockholm, Sweden

Corresponding author: Ulf Jonsson, Department of Neuroscience, Child and Adolescent Psychiatry, Uppsala University, SE-751 85 Uppsala, Sweden, ulf.jonsson@ neuro.uu.se

Note: this is a personal version, created by Anna Goodman, of the text of the accepted journal article. It reflects all changes made in the peer review process, but does not incorporate any minor modifications made at the proof stage. The complete citation for the final journal article is:

- Jonsson, U., Goodman, A., Von Knorring, A.-L., Von Knorring, L. \& Koupil, I. 2012. School performance and hospital admission due to depression: a threegenerational study of social causation and social selection Soc Psychiatry Psychiatr Epidemiol, 47, 1695-1706

- DOI: 10.1007/s00127-012-0476-y

Copyright (C) and Moral Rights for this paper are retained by the individual authors and/or other copyright owners 


\section{$\underline{\text { Abstract }}$}

Purpose: Both "social causation" and "social selection" offer plausible explanations for an association between education and mental health. We aimed to explore these processes in unipolar depression, with a specific focus on school performance and family tradition of education.

Method: Grandchildren ( $n=28,089,49 \%$ female, aged 13-47 years in 2002) of a cohort born in Uppsala, Sweden, in 1915-1929 were studied in national registers. We obtained data on final grade point average (GPA) in compulsory school, hospitalizations for unipolar depression, grandparental/parental education and other parental social characteristics. Hospitalization in adolescence and adulthood were studied separately, as were hospitalization for depression with or without a lifetime externalizing disorder.

Results: Low compulsory school GPA (1-2 SD or >2 SD below average vs. average GPA) was associated with increased rate of adolescent hospitalization for unipolar depression, both with externalizing comorbidity (hazard ratio (HR) point estimates of 6680) and without (HR point estimates of 4-6). By contrast, low GPA was only associated with first-time hospitalization in adulthood for the subgroup with externalizing comorbidity (HR point estimates of 4-6). These associations were largely independent of family education and social characteristics. Overall, low parental/grandparental education was not related to increased rates of hospitalization.

Conclusion: The association between school performance and hospitalization for depression depended on adolescent hospitalization or externalizing comorbidity, suggesting that disorders with an early onset are decisive. Contrary to the social patterning of many health outcomes, low grandparental/parental education did not appear to increase the rate of hospitalization for unipolar depression in the offspring.

Keywords: unipolar depression; social selection, social causation, externalizing disorders; school performance 


\section{$\underline{\text { Introduction }}$}

Numerous studies have linked both internalizing disorders (e.g. unipolar depression) and externalizing disorders (e.g. conduct disorder and ADHD) to educational problems [1-7]. These disorders often have an onset in childhood or adolescence [8,9], and a prolonged trajectory or a recurrent course [10-13]. They are thus likely to be interconnected with school problems over long stretches of time. It is not clear to what extent the trajectories of the disorders interfere with school performance or, alternatively, to what extent poor performance at school triggers, exacerbates, or indirectly leads to mental health problems. It is also unclear to what extent socioeconomic disadvantage and associated adversities precede both mental disorders and school problems. All three of these scenarios are plausible, and may also interact with each other in a self-reinforcing feedback loop from childhood into adulthood.

The theories of "social causation" and "social selection" have been used extensively to study the relationship between mental disorders and social conditions. The "social causation" thesis postulates that low socioeconomic status (SES) plays a causal role in the aetiology of mental disorders. According to this line of reasoning, socioeconomic or educational disadvantages of the family of origin would lead to poor mental health because of the stress and adversity associated with low SES during childhood. When mental health is studied in relation to school performance, the family tradition of education (e.g. the educational history parents and grandparents) could be of particular importance. Swedish national statistics illustrate that low parental education is associated with substantially poorer school performance [14]. To some extent, an association between school performance and mental health might therefore be explained by educational history within the family.

However, a causal effect of school performance per se upon mental health is consistent with recent large-scale register studies in Sweden, reporting that poor school grades in compulsory school predict subsequent suicide $[15,16]$ as well as hospital admission due to self-inflicted injury [17] in national birth cohorts followed to early adulthood. The rate increases in a step-wise manner with decreasing grade point average, even after adjustment for possible socioeconomic confounders. The mechanisms behind this pattern are not known, but hampered social attainment could be one possible explanation. School performance is an important predictor of subsequent educational attainment, which in turn is a major factor in social mobility [18] and an important predictor of subsequent health $[19,20]$. It has been suggested that education promotes good health in part by mitigating social stressors and strengthening individuals' social networks [21]. A low level of education could therefore exert a negative influence on mental health throughout adulthood.

The thesis of "social selection" or "social drift", on the other hand, argues that mental disorders hinder social attainment (e.g. by interfering with school performance) and lead to a downward shift in SES. In support of this thesis, a recent report from the 1958 British birth cohort highlights the large effects that poor mental health in childhood had on intergenerational and within- generation social mobility at age 50 [22]. Likewise, 
previous analyses of the same cohort reported that childhood internalizing and externalizing disorders were associated with reduced upward social mobility and manual adult social-economic position at age 45 [13].

Previous research has suggested that social causation and social selection processes vary in importance between categories of mental disorders [23-25]. Externalizing disorders in particular seem to be associated with low SES during childhood and adolescence, [23,24] while the relationship between low SES and internalizing disorders partly seems to be explained by comorbidity with externalizing problems [26]. Although both externalizing and internalizing disorders are likely to be detrimental to school results, externalizing disorders in particular could be key determinants of educational problems [23,24]. A large body of research on children, adolescents, and young adults indicates that externalizing disorders are closely related to significant academic underachievement and also to impaired school functioning (including absenteeism, grade retention and dropout) $[2,3,6,23]$.

In the present study we utilized register data on hospitalization for unipolar depression, with or without externalizing comorbidity, to explore processes of "social causation" and "social selection". We focused specifically on how school performance and family tradition of education are related to hospitalization for depression, with separate analyses for hospitalization occurring in adolescence and adulthood. Three research questions were addressed:

1. How is grandparental and parental education related to adolescent and adult hospitalization for depression in the grandchildren?

2. Among the grandchildren, how is their own school performance related to adolescent and adult hospitalization for depression, after accounting for parental and grandparental education?

3. What relevance does externalizing comorbidity have for question one and question two?

\section{Material and methods}

\section{Study participants}

Our study participants were the grandchildren of members of the Uppsala Birth Cohort (UBCoS). The original UBCoS consists of 14192 males and females born in Uppsala University Hospital from 1915 to 1929 ('grandparent' generation). Using the Swedish Multi-Generation Register we traced all descendants of these UBCoS members born 1932-2002 and registered in Sweden at least once during 1961-2002. The MultiGeneration Register also provided information about the identity of UBCoS descendants' other biological (or adoptive) parent. We therefore had information on both parents of our study participant and at least one (often two or more) of the four grandparents. The study was approved by the regional Ethics Committee in Stockholm. 
Figure 1 outlines the inclusion of participants for this particular study. Separate analyses were performed for first-time hospitalization in adolescence (age 12-17 years) and adulthood (age $\geq 18$ years). Individuals born between 1956 and 1989 were included, meaning that all participants were under 18 (the upper limit of our definition of adolescence) in 1973, the first year that the Swedish Hospital Discharge Register had complete national coverage. In addition, all participants were over 12 (the lower limit of our definition of adolescence) at the end of the follow-up period. Between 1956 and 1989, 29509 grandchildren of UBCoS were born. We excluded those who were born outside of Sweden $(\mathrm{N}=349)$, were adopted into UBCoS families $(\mathrm{N}=429)$, died or emigrated before age 12 or before $1973(\mathrm{~N}=595)$, or had a lifetime diagnosis of schizophrenia or bipolar disorder $(\mathrm{N}=47)$. For the analyses of first-time hospitalization in adulthood, we also excluded all with a first diagnosis of depression before age $18(\mathrm{~N}=46)$, those who had not turned eighteen before the end of the follow-up ( $\mathrm{N}=5911)$, or those who had died or emigrated before age $18(\mathrm{~N}=110)$. In the adolescent hospitalization analyses participants were followed up for a mean of 5.5 years $(\mathrm{SD}=1.2$ years, range 0.01-6.0 years). In the adult hospitalization analyses, participants were followed up for a mean of 9.4 years $(\mathrm{SD}=6.1$ years, range $0.3-29.0$ years). 
Figure 1: Inclusion and exclusion criteria, and definitions of the samples for the different analyses.

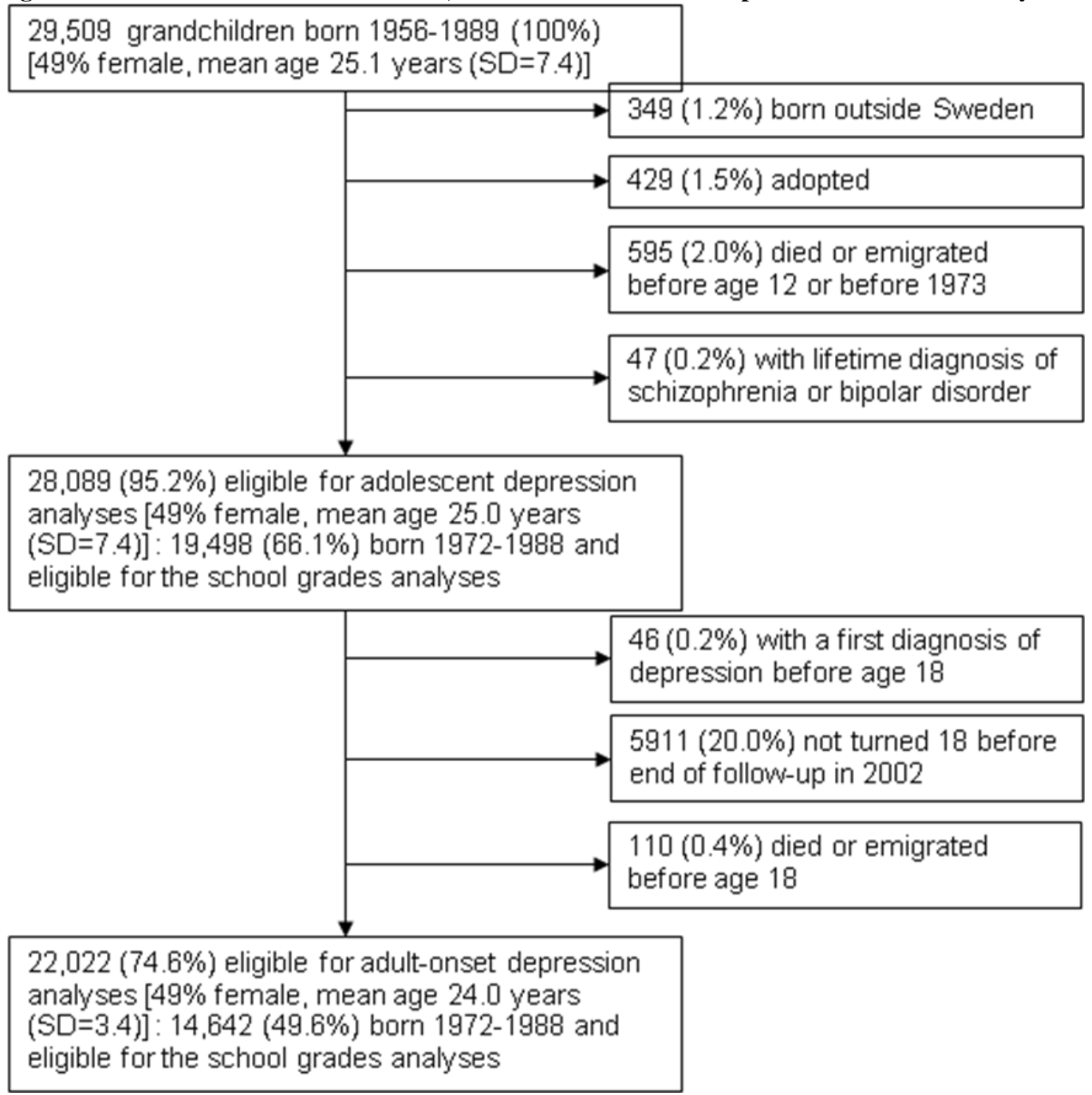

SD standard deviation. 


\section{Definitions of unipolar depression and externalizing disorders}

We obtained information on psychiatric diagnoses through linkage to the Swedish Hospital Discharge Register, which had complete national coverage from 1973. Unipolar depression was defined as diagnostic codes F32 (depressive episode) or F33 (recurrent depressive disorder) in the International Classification of Diseases and Related Health Problems $10^{\text {th }}$ Revision (ICD-10) (http://apps.who.int/classifications/icd10/browse/2010/en) [27], or corresponding diagnoses in earlier versions of ICD. Participants were classified as having unipolar depression if one of these codes featured in their hospitalization discharge records as either a main or a secondary diagnosis from 1973 onwards. Participants with a lifetime ICD-10 code of F30 (manic episode), F31 (bipolar affective disorder), F20 (schizophrenia), or F25 (schizoaffective disorder), or corresponding codes in earlier versions of the ICD were excluded.

We further categorised the subjects with unipolar depression depending on whether they had a registered lifetime externalising disorder. Externalizing disorder was defined by the following ICD-10 codes (or corresponding diagnoses in earlier versions): F10-19 (mental and behavioural disorders due to psychoactive substance use); F55 (abuse of nondependence-producing substances); F60.2 (dissocial personality disorder); F60.3 (emotionally unstable personality disorder); F63 (habit and impulse disorders); F90 (hyperkinetic disorders); and F91 (conduct disorders).

We also used the Swedish Hospital Discharge Register to obtain information about parental depression or externalizing disorders, using the same definitions.

\section{Grandparental and parental variables}

Grandparental education was obtained from 1960 census if available, or otherwise from the 1970 census. Each individual's education was categorised as either "elementary" or "higher (upper secondary and above)". For each grandchild, we then grouped the grandparents on the mother's and the father's side together to make variables for "any grandmother with higher education" and "any grandfather with higher education". Information on parental educational level was obtained from the census and the Longitudinal Database for Education, Income and Occupation (LOUISE) databases and was analyzed in 3 categories as "elementary" ( $<10$ years in education), "secondary" (1112 years), and "postsecondary" ( $\geq 13$ years).

Data on mother's civil status and parental employment status was obtained from the 1990 census. Mother's civil status was divided into three categories: "married or living together"; "single or separated"; and "widowed or divorced". Parental employment was grouped into two categories as "no parent unemployed" vs. "at least one parent unemployed". 


\section{School performance}

The Swedish National Agency for Education provided the grades earned during the last year of compulsory school (typically completed the calendar year they turned 16) for all participants born 1972-1988. The data were based on 2 different grading systems. In the first study period, Sweden had a national relative grading system. Grades ranged from 1 to 5. In the school year 1995-1996, a new criterion-referenced grading system was introduced, with grades divided into 4 levels: IG (not pass), G (pass), VG (pass with distinction), and MVG (pass with special distinction) and pre-specified skills required for different levels [28].

Grade point average (GPA) was calculated for all students by their schools based upon 16 to 18 standard subjects. In order to combine these averages across the two different grading systems we standardised each system separately, then combined the standardised scores. The GPA's were divided into four categories: $\geq 1$ SD above mean; 0-1 SD from mean; 1-2 SD below mean; and >2 SD below mean. Our substantive findings were similar in a sensitivity analysis which examined associations with the two grading systems separately.

\section{Data analyses}

We studied the incidence of hospitalization for unipolar depression using Cox proportional hazards models, using age as the time variable and also adjusting for study period (1973-1993, 1993-1998, 1998-2002) and gender. We performed separate analyses for depression during adolescence and adult-onset depression. In the adolescent depression analyses, follow-up started on the $12^{\text {th }}$ birthday or on $1^{\text {st }}$ January 1973 (whichever came later). Follow-up then continued until the date of death, emigration, depression diagnosis, 31 December 2002 or the child's 18th birthday. Children with a diagnosis of depression before their $12^{\text {th }}$ birthday $(\mathrm{N}=7)$ were not excluded, but were only counted as having adolescent depression if they were hospitalised again after the age of $12(\mathrm{~N}=2)$. In the adult-onset analyses, follow-up started on the 18th birthday or on $1^{\text {st }}$ January 1973, and continued until the date of death, emigration, depression diagnosis or 31 December 2002. For these analyses we excluded all those who had a diagnosis of depression before age 18 (including before age 12). All analyses were performed for any unipolar depressive diagnoses as well as divided into those with and without an externalizing diagnosis.

Our first set of analyses investigated the association of parental and grandparental education with grandchild hospitalization for depression. Grandparental education and parental education were entered as independent variables (thereby adjusting for each other), together with parental unemployment and maternal civil status. Hospitalization for depression was the dependent variable. The analyses were divided into adolescent and adult hospitalization. In a second set of analyses, we investigated the association of the grandchildren's own GPA and hospitalization for depression. These analyses were identical to the first set, but with GPA ("0-1 SD from mean" as reference category) as an additional independent variable. All the above analyses were also computed with parental 
hospitalization for unipolar depression or externalizing disorders as an additional independent variable.

The frequency of missing data ranged from $0-4.1 \%$ for all explanatory variables examined. We used multiple imputation by chained equations to impute missing values under an assumption of missing at random [29], using the ICE command in Strata 11. We used five imputations for these models, including in our imputation models all explanatory and outcome variables which we ever used in our substantive models of interest. Our substantive findings were unchanged in a sensitivity analysis restricted to those with full data. All standard errors in Cox models were calculated with clustering by the participant's mother, in order to allow for potential correlations due to similarity between siblings. All the analyses were conducted using Strata 11.

\section{Results}

\section{Descriptive data}

In total, 41 participants (29 female) received a depression diagnosis aged 12-17 (mean 15.7 years, SD 2.2), corresponding to a crude incidence rate of 27/100 000 person years (95\%CI 20 to 36). Of these, 10 (5 female) also received a diagnosis of externalising disorder over the course of their lifetimes, and 7 of these were substance use disorders. All cases of externalizing disorders were diagnosed in adolescence or young adulthood (mean 15.8, SD 1.9, range 14-19 years).

In total, 126 participants (73 female) received a first diagnosis of depression after turning 18 (mean 25.2 years, SD 5.7, range 18-42), giving a crude incidence rate of 61/100 000 person years (95\%CI 51 to 73 ). Of these, 45 (19 female) also received a diagnosis of externalising disorder over the course of their lifetimes, 30 of which were substance use disorders. Two cases of externalizing diagnoses were diagnosed below the age of 18 (age 8 and 15) while the remainder were diagnosed at ages 18-42 (mean 25.6 years, SD 7.4). Overall, the externalizing disorders were generally registered close in time to the diagnoses of unipolar depression (mean 2.7 years difference, SD 4.2, range 0-18). Only the results from the fully adjusted models are presented (Table 1-3). Results were generally similar in analyses with minimal adjustment only for age, study period and gender. All analyses were also repeated with additional adjustment for parental unipolar depression and externalizing disorders, but this had little effect on the overall findings (result not shown).

\section{Grandparental education and hospitalization due to unipolar depression}

Low grandparental education did not generally predict hospitalization for depression, the only exception being that elementary level grandfathers' education predicted a higher rate of adult hospitalization in the context of a lifetime externalizing diagnosis ( $\mathrm{HR}=4.63$; 95\%CI 1.59 to 13.5 ). Regarding grandmothers' education, the pattern was the opposite: elementary level grandmothers' education predicted a lower rate of hospitalization for depression with a lifetime externalizing diagnoses in adolescence $(\mathrm{HR}=0.16$; 95\% CI 0.05 to 0.47 ) as well as in adulthood ( $\mathrm{HR}=0.25$; $95 \% \mathrm{CI} 0.08$ to 0.74$)$. The proportion of 
grandparents (grandmother in particular) with education above elementary level was generally low and the statistical power of these analyses was limited (Table 1).

\section{Parental education and hospitalization due to unipolar depression}

Low parental education did not predict hospitalization for depression in either adolescence or adulthood. On the contrary, mother's education to postsecondary (vs. secondary) level was associated with an increased hazard ration of hospitalization for depression in adulthood ( $\mathrm{HR}=2.17$; 95\%CI 1.34 to 3.53), independent of grandparental education and other family social characteristics (Table 2). There were no clear associations between father's education and hospitalization. 
Table 1: Cox regression analyses of associations between grandparental education and adolescent and adult hospitalization for depression in third-generation descendants, subdivided depending on lifetime externalizing disorders ( $N=28089$ for the adolescent analyses and $\mathrm{N}=22 \mathrm{022}$ for the adult analyses)

HR=hazard ratio. Pyrs=person-years. a Adjusted for age, study period and gender, grandparental education (grandfathers' adjusted for grandmothers', and vice versa), parental education, parental

\begin{tabular}{|c|c|c|c|c|c|c|c|c|c|c|}
\hline & \multirow[t]{2}{*}{$\mathrm{N}$} & \multicolumn{3}{|c|}{ All depression diagnoses } & \multicolumn{3}{|c|}{$\begin{array}{l}\text { Depression diagnoses without a lifetime } \\
\text { externalizing diagnoses }\end{array}$} & \multicolumn{3}{|c|}{$\begin{array}{l}\text { Depression diagnoses with a lifetime externalizing } \\
\text { diagnoses }\end{array}$} \\
\hline & & $\begin{array}{l}\text { Number } \\
\text { of cases }\end{array}$ & $\begin{array}{l}\text { Crude } \\
\text { incidence/ } \\
100000 \text { pyrs }\end{array}$ & $\begin{array}{l}\text { HR adjusted for } \\
\text { family factors }{ }^{\text {a }}\end{array}$ & $\begin{array}{l}\text { Number } \\
\text { of cases }\end{array}$ & $\begin{array}{l}\text { Crude } \\
\text { incidence/ } \\
100000 \text { pyrs }\end{array}$ & $\begin{array}{l}\text { HR adjusted for } \\
\text { family factors }{ }^{\text {a }}\end{array}$ & $\begin{array}{l}\text { Number } \\
\text { of events }\end{array}$ & $\begin{array}{l}\text { Crude } \\
\text { incidence/ } \\
100000 \text { pyrs }\end{array}$ & $\begin{array}{l}\text { HR adjusted for } \\
\text { family factors }{ }^{\text {a }}\end{array}$ \\
\hline \multirow{2}{*}{\multicolumn{11}{|c|}{$\begin{array}{l}\text { Adolescent hospitalization } \\
\text { Grandmothers' education }\end{array}$}} \\
\hline & & & & & & & & & & \\
\hline Any above elementary & 1300 & 4 & 60.1 & 1 & 2 & 30.1 & 1 & 2 & 30.0 & 1 \\
\hline Both elementary & 26454 & 37 & 25.6 & $0.63(0.19,2.08)$ & 29 & 20.0 & $1.15(0.22,5.88)$ & 8 & 5.6 & $0.16(0.05,0.47)$ \\
\hline \multicolumn{11}{|l|}{ Grandfathers' education } \\
\hline Any above elementary & 3923 & 9 & 43.9 & 1 & 7 & 34.2 & 1 & 2 & 9.8 & 1 \\
\hline Both elementary & 23148 & 31 & 24.4 & $0.67(0.28,1.58)$ & 24 & 18.9 & $0.52(0.20,1.37)$ & 7 & 5.5 & $1.64(0.48,5.59)$ \\
\hline \multicolumn{11}{|l|}{ Adult hospitalization } \\
\hline \multicolumn{11}{|l|}{ Grandmothers' education } \\
\hline Any above elementary & 840 & 3 & 56.7 & 1 & 1 & 18.9 & 1 & 2 & 37.8 & 1 \\
\hline Both elementary & 20884 & 120 & 60.8 & $1.06(0.31,3.64)$ & 78 & 39.5 & $3.05(0.40,23.11)$ & 42 & 21.3 & $0.25(0.08,0.74)$ \\
\hline \multicolumn{11}{|l|}{ Grandfathers' education } \\
\hline Any above elementary & 2715 & 10 & 52.0 & 1 & 8 & 41.6 & 1 & 2 & 10.4 & 1 \\
\hline Both elementary & 18386 & 107 & 60.9 & $1.55(0.74,3.24)$ & 66 & 37.6 & $1.06(0.46,2.44)$ & 41 & 23.3 & $4.63(1.59,13.45)$ \\
\hline
\end{tabular}
unemployment, and maternal civil status. Multiple imputation was used to include participants with missing data in the regression 
Table 2. Cox regression analyses of associations between parental education and adolescent and adult hospitalization for depression, subdivided depending on lifetime externalizing diagnoses ( $N=28089$ for the adolescent analyses and $N=22022$ for the adult analyses)

\begin{tabular}{|c|c|c|c|c|c|c|c|c|c|c|}
\hline & \multirow[t]{2}{*}{$\mathrm{N}$} & \multicolumn{3}{|c|}{ All depression diagnoses } & \multicolumn{3}{|c|}{$\begin{array}{l}\text { Depression diagnoses without a lifetime externalizing } \\
\text { diagnoses }\end{array}$} & \multicolumn{3}{|c|}{$\begin{array}{l}\text { Depression diagnoses with a lifetime } \\
\text { externalizing diagnoses }\end{array}$} \\
\hline & & $\begin{array}{l}\text { Number } \\
\text { of cases }\end{array}$ & $\begin{array}{l}\text { Crude incid./ } \\
100.000 \text { pyrs }\end{array}$ & $\begin{array}{l}\text { HR adjusted for } \\
\text { family factors }{ }^{a}\end{array}$ & $\begin{array}{l}\text { Number } \\
\text { of cases }\end{array}$ & $\begin{array}{l}\text { Crude incid./ } \\
100000 \text { pyrs }\end{array}$ & $\begin{array}{l}\text { HR adjusted for family } \\
\text { factors }{ }^{\mathrm{b}}\end{array}$ & $\begin{array}{l}\text { Number } \\
\text { of cases }\end{array}$ & $\begin{array}{l}\text { Crude incid./ } \\
100000 \text { pyrs }\end{array}$ & $\begin{array}{l}\text { HR adjusted for } \\
\text { family factors }{ }^{b}\end{array}$ \\
\hline \multicolumn{11}{|c|}{ Adolescent hospitalization } \\
\hline \multicolumn{11}{|l|}{ Mother's education } \\
\hline Post secondary & 8447 & 13 & 28.8 & $0.94(0.42,2.09)$ & 10 & 22.1 & $1.05(0.39,2.82)$ & 1 & 6.6 & $0.66(0.18,2.35)$ \\
\hline Secondary & 13270 & 21 & 29.1 & 1 & 15 & 20.8 & 1 & 6 & 8.3 & 1 \\
\hline Elementary & 5874 & 6 & 18.3 & $0.59(0.24,1.46)$ & 10 & 15.2 & $0.70(0.26,1.89)$ & 3 & 6.6 & $0.33(0.04,2.84)$ \\
\hline \multicolumn{11}{|l|}{ Father's education } \\
\hline Post secondary & 7600 & 11 & 27.3 & $0.91(0.37,2.26)$ & 8 & 19.9 & $0.87(0.28,2.71)$ & 3 & 7.3 & $1.06(0.29,3.82)$ \\
\hline Secondary & 11926 & 15 & 23.1 & 1 & 11 & 16.9 & 1 & 4 & 6.2 & 1 \\
\hline Elementary & 7413 & 14 & 33.9 & $1.71(0.82,3.56)$ & 11 & 26.7 & $1.85(0.79,4.32)$ & 3 & 7.4 & $1.33(0.30,5.83)$ \\
\hline \multicolumn{11}{|c|}{ Adult hospitalization } \\
\hline \multicolumn{11}{|l|}{ Mother's education } \\
\hline Post secondary & 6239 & 42 & 88.2 & $2.17(1.34,3.53)$ & 27 & 56.7 & $2.00(1.12,3.59)$ & 15 & 31.5 & $2.49(1.10,5.62)$ \\
\hline Secondary & 10337 & 44 & 46.2 & 1 & 27 & 28.4 & 1 & 17 & 17.9 & 1 \\
\hline Elementary & 4961 & 47 & 66.4 & $1.38(0.88,2.17)$ & 26 & 46.6 & $1.67(0.96,2.90)$ & 11 & 19.7 & $0.98(0.46,2.09)$ \\
\hline \multicolumn{11}{|l|}{ Father's education } \\
\hline Post secondary & 5480 & 26 & 64.3 & $0.96(0.55,1.70)$ & 19 & 47.0 & $1.10(0.58,2.07)$ & 7 & 17.3 & $0.74(0.27,2.05)$ \\
\hline Secondary & 9275 & 48 & 56.8 & 1 & 31 & 36.7 & 1 & 17 & 20.1 & 1 \\
\hline Elementary & 6179 & 42 & 62.9 & $1.13(0.73,1.74)$ & 26 & 39.0 & $1.06(0.62,1.80)$ & 16 & 24.0 & $1.26(0.60,2.66)$ \\
\hline
\end{tabular}

HR=hazard ratio. Pyrs=person-years. ${ }^{\text {a }}$ Adjusted for age, study period and gender, grandparental education, parental education (fathers' adjusted for mothers', and vice versa), parental unemployment, and maternal civil status. Multiple imputation was used to include participants with missing data in the regression analyses. 


\section{Grades in compulsory school and hospitalization due to unipolar depression}

Low final GPA in compulsory school was associated with a higher rate of hospitalization for depression in adolescence (Table 3). This association was particularly strong in the few cases with adolescent depression and an externalizing disorder; out of 7 cases with this combination, 6 had a GPA of 1 standard deviation (SD) below population mean or lower (HR point estimates $>60$ ). However, the association was also clear for those without an externalizing disorder (HR point estimates 4-6).

Low GPA was also associated with first time hospitalization in adulthood (Table 3). This association seemed to be attributable to the subgroup with both depression and an externalizing disorder. Out of the 19 participants with this combination, only 1 had a GPA of 1 SD or more above the population average, while 8 had a GPA 1 SD or more below the average (HR point estimates 4-6). 
Table 3: Cox regression analyses of the association between final grade point average in compulsory school and hospitalization in adolescence and adulthood, subdivided depending on lifetime externalizing disorder ( $N=19498$ for the adolescent analyses and $N=14642$ for the adult analyses)

\begin{tabular}{|c|c|c|c|c|c|c|c|c|c|c|}
\hline & \multirow[t]{2}{*}{$\mathrm{N}$} & \multicolumn{3}{|c|}{ All depression diagnoses } & \multicolumn{3}{|c|}{$\begin{array}{l}\text { Depression diagnoses without a lifetime } \\
\text { externalizing diagnoses }\end{array}$} & \multicolumn{3}{|c|}{$\begin{array}{l}\text { Depression diagnoses with a lifetime externalizing } \\
\text { diagnoses }\end{array}$} \\
\hline & & $\begin{array}{l}\text { Number } \\
\text { of cases }\end{array}$ & $\begin{array}{l}\text { Crude } \\
\text { incidence/ } \\
100000 \text { pyrs }\end{array}$ & $\begin{array}{l}\text { HR adjusted for } \\
\text { family factors }{ }^{\text {a }}\end{array}$ & $\begin{array}{l}\text { Number } \\
\text { of cases }\end{array}$ & $\begin{array}{l}\text { Crude } \\
\text { incidence/ } \\
100000 \text { pyrs }\end{array}$ & $\begin{array}{l}\text { HR adjusted for } \\
\text { family factors }{ }^{\text {a }}\end{array}$ & $\begin{array}{l}\text { Number } \\
\text { of cases }\end{array}$ & $\begin{array}{l}\text { Crude } \\
\text { incidence/ } \\
100000 \text { pyrs }\end{array}$ & $\begin{array}{l}\text { HR adjusted for family } \\
\text { factors }^{\text {a }}\end{array}$ \\
\hline \multirow{2}{*}{\multicolumn{11}{|c|}{ Adolescent hospitalization }} \\
\hline & & \multicolumn{9}{|c|}{ Compulsory school GPA } \\
\hline High (> 1 SD above mean) & 2763 & 4 & 26.5 & $1.26(0.38,4.18)$ & 4 & 26.5 & $1.45(0.42,4.99)$ & 0 & 0.0 & [no cases] \\
\hline Average (0-1 SD from mean) & 13663 & 11 & 14.6 & 1 & 10 & 13.3 & 1 & 1 & 1.3 & 1 \\
\hline Low (1-2 SD below mean) & 1880 & 8 & 74.4 & $7.98(2.77,22.97)$ & 4 & 37.2 & $4.43(1.23,15.98)$ & 4 & 37.2 & $66.72(6.08,732.00)$ \\
\hline Very low ( $>2$ SD below mean) & 677 & 4 & 110.3 & $10.09(2.62,38.82)$ & 2 & 55.1 & $5.70(1.09,29.70)$ & 2 & 55.1 & $80.13(7.03,913.56)$ \\
\hline \multicolumn{11}{|l|}{ Adult hospitalization } \\
\hline \multicolumn{11}{|l|}{ Compulsory school GPA } \\
\hline High ( $\geq 1$ SD above mean) & 2018 & 9 & 76.8 & $1.09(0.51,2.36)$ & 8 & 68.3 & $1.34(0.57,3.14)$ & 1 & 8.5 & $0.44(0.05,3.57)$ \\
\hline Average $(<1 \mathrm{SD}$ from mean $)$ & 10255 & 33 & 55.6 & 1 & 23 & 38.7 & 1 & 10 & 16.8 & 1 \\
\hline Low (1-2 SD below mean) & 1596 & 11 & 103.2 & $2.34(1.15,4.77)$ & 5 & 46.9 & $1.60(0.59,4.32)$ & 6 & 56.3 & $4.03(1.37,11.81)$ \\
\hline Very low ( $>2$ SD below mean) & 445 & 3 & 127.4 & $2.85(0.80,10.08)$ & 1 & 42.5 & $1.46(0.17,12.73)$ & 2 & 84.9 & $6.03(1.27,28.67)$ \\
\hline
\end{tabular}
with missing data in the regression analyses 


\section{$\underline{\text { Other social characteristics and additional regression models }}$}

Mother's civil status was associated with hospitalization for depression in adolescence, such that the rate was higher in those with a widowed or divorced mother vs. a married mother ( $\mathrm{HR}=3.27$; $95 \% \mathrm{CCI} 1.69$ to 6.30$)$. This was the case regarding both depression only (2.90; 95\%CI 1.33 to 6.31$)$ and depression in combination with an externalizing disorder (4.68; 95\% CI 1.37 to 15.96). A similar, albeit weaker, association was also observed with respect to first-time hospitalization for depression in adulthood (1.52; $95 \%$ CI 1.03 to 2.23 ).

Parental unemployment was associated with hospitalization for depression in adulthood (2.08; 95\% CI 1.36 to 3.16) and, at borderline statistical significance, adolescence (2.01; 95\%CI 0.98 to 4.13 ). The pattern was similar for the participants with and without an externalizing diagnosis.

\section{$\underline{\text { Discussion }}$}

The present three-generation study is a contribution to the ongoing debate on school performance and mental health. Contrary to the social patterning of many health outcomes, the present study found no evidence that low grandparental or parental education increases the rate of hospitalization for depression in the offspring. However, clear negative associations between own school grades and hospitalization for depression were observed. These associations were largely independent of grandparental and parental education and other parental characteristics, and were particularly robust regarding adolescent hospitalization. For first-time hospitalized in adulthood, the association with school grades was restricted to those who also had an externalizing comorbidity. Our results thus indicated that age at onset and externalizing comorbidity of depression could be decisive factors in the association between school performance and severe unipolar depression.

The analyses involving family tradition of education generally did not offer support to the traditional theory of "social causation" which hypothesises that socio-economic disadvantage causes mental health problems for individuals and their descendants. This is in line with some previous studies of social causation in unipolar depression [30,23], but contradictory to others $[31,24]$. Interestingly, some of our results even seem to contradict "social causation" outright. Grandmother's education above elementary level increased the rate of both adolescent and adult hospitalization for depression in the context of externalizing disorders. A similar association was also observed between mother's postsecondary education (vs. secondary education) and adult hospitalization for depression both with and without comorbid externalising disorder. Although unexpected, these results are broadly consistent with recent findings from this same cohort showing an increased rate of eating disorders among granddaughters of women with higher education [32].

These associations may partly reflect socioeconomic differences in healthcare seeking behaviour or in access to mental health services, although studies of this issue have 
yielded somewhat conflicting results [33-35]. It should be noted that access to healthcare in Sweden was generally high throughout the study period and that hospitalization in particular incurred no financial charges. Given the specificity of the effect of high education as opposed to other forms of social advantage (see below), we believe a genuine negative effect is also possible, perhaps mediated by high parental demands. While the results on family tradition of education might speak against "social causation", the broader context of social disadvantage seemed to be of importance. Parental unemployment was associated with hospitalization for depression in both adolescence and adulthood, and mother's divorce or widowhood was associated with hospitalization in adolescence. It is probable that these factors are markers of general adversity in childhood and adolescence, which has been shown to be linked to depression through continued stress and stress sensitization [36,37]. It should also be noted that poor mental health is related to both unemployment [38] and divorce [39]. Thus, these factors could to some extent be markers of poor mental health in the parents. Further, loss of a parent early in life has previously been identified as a risk factor for major depression [40,41]. Low GPA was strongly associated with hospitalization for depression in adolescence, such that adolescents with a GPA of more than 1 SD below the mean were at increased risk. Not surprisingly, this association was particularly strong for those with a comorbid externalizing disorder (two-thirds of which were substance use disorders). Given the established effect of externalising disorders upon school performance [2-4], this seems likely to reflect in large part the impact of ongoing, severe mental health problems upon school performance. We cannot, however, rule out the possibility that poor school performance has a direct impact on mental health during adolescence. School failure might undermine self-esteem and thereby increase the risk of adolescent depression, disruptive behaviour and substance misuse. Further, ongoing psychosocial problems could have a negative impact on both school performance and mental health.

The association between school grades and first-time hospitalization in adulthood seemed to be restricted to the subgroup that also had an externalizing disorder (predominantly substance use disorders), while no association between school grades and adult hospitalization for depression without an externalizing diagnosis was observed. We interpret this intriguing pattern as suggesting a process of "social selection" driven by a lifespan trajectory of externalising disorders. Externalizing symptoms typically have an onset in childhood [42], and the trajectories of externalizing symptoms during childhood and adolescent predict adolescent and adult mental disorders within the (disruptive disorders, but also substance use disorders, anxiety disorders, and mood disorders) $[43,10]$. It is therefore plausible that externalizing problems were to some extent present across the school years in those with adult-onset depression comorbid with externalising disorders, and that this had a negative effect on performance. School failure, in its turn, might intensify existing externalizing problems and trigger substance use disorders. By contrast, the onset of depression is distributed throughout the lifespan, with a roughly linear increase of cumulative prevalence from early adolescence to early adulthood [44]. Thus although many adults in our sample may only have been hospitalized for depression some years after its first onset, this first onset was probably in many cases after age 15/16 and so too late to affect their school performance in compulsory school. 
In the present study, about a quarter of those with an adolescent or adult-onset depression diagnosis also had an externalizing diagnosis. This substantial comorbidity is in line with other studies. For example, in two nationally-representative British samples $31 \%$ of adolescents aged 12-16 with depression also had an externalising disorder [45,46] (comorbidity calculation by authors). Similarly in a nationally representative US sample of adults, $24 \%$ of those with lifetime major depressive disorder had a lifetime substance use disorder, while $30 \%$ had a lifetime impulse control disorder [47].

Our findings also raise questions about how far externalising trajectories could explain the results of recent Swedish register studies reporting that low school performance predicts subsequent self-harm and suicide [15-17]. Recent research has suggested that disorders characterized by poor impulse control (such as conduct disorder or substance use disorders) can have a decisive influence upon whether suicidal ideation results in an actual suicide attempt [48]. We therefore believe further research is warranted into whether other forms of mental ill-health show the same pattern of results as the present study.

\section{$\underline{\text { Limitations }}$}

The results should be viewed in the light of some limitations, most of which relate to our reliance on hospitalization records (use of inpatient care) to identify depression and externalizing disorders. The diagnoses of depression and externalizing disorders were generally recorded close in time, suggesting that both were often observed when one or both disorders were severe enough to warrant hospitalization. It is therefore probable that some of the participants with depression that were classified as not having a lifetime externalizing disorder actually did fill the criteria for externalizing disorders at some time, but were not treated for this in an inpatient setting. Similarly, it is probable that some participants who were treated for depression for the first time in adulthood actually had an onset in adolescence. Yet despite these possible misclassifications there was little evidence that poor school performance predicted adult hospitalization for depression, unless a comorbid externalizing disorder was present. This further underlines our conclusion that poor school performance per se does not seem to increase the rate of subsequent severe depression.

A second limitation associated with using inpatient records is that only a small proportion of cases of unipolar depression are treated in an inpatient setting. We did not have information on the severity of the recorded cases of depression, but hospitalization usually indicates relatively high severity. It is unclear to what extent our results can be generalized to the more prevalent mild or moderate cases of depression in the general population. Another drawback is the possibility of socioeconomic differences in how individuals seek treatment or in how professionals apply hospital admission criteria. If individuals with higher SES are more likely to seek treatment or to receive treatment for their depressive episodes in an inpatient setting then social causation could be underestimated in our analyses, and vice versa. 
Finally we may have underestimated the importance of some family background due to the small number of cases available for some analyses (especially regarding adolescent depression) and due to restrictions in the measurements available to us. In particular, data on mother's civil status and parental employment status was obtained from the 1990 census. Thus, these characteristics were measured when the participants were at different ages, ranging from 1 to 34 years. This informed our decision not to make these a major focus of this study, but we recognise that our analyses would have been enriched by more detailed and repeated measures during pre-defined sensitive periods in childhood.

\section{$\underline{\text { Conclusion }}$}

The association between school performance and hospitalization for depression seems mainly to be attributable to mental health problems with an early onset, in line with the "social selection" hypotheses. While the analyses of grandparental/parental education and hospitalization for depression in general did not suggest "social causation" as the main mechanism generating association between education and depression in our study, the broader social context of e.g. mother's civil status or parental unemployment was of importance.

\section{Conflict of interest}

None

\section{$\underline{\text { References }}$}

1. Jonsson U, Bohman H, Hjern A, von Knorring L, Olsson G, von Knorring AL (2010) Subsequent higher education after adolescent depression: a 15-year follow-up register study. Eur Psychiatry 25 (7):396-401. doi:S0924-9338(10)00079-9 [pii] 10.1016/j.eurpsy.2010.01.016

2. McLeod JD, Kaiser K (2004) Childhood emotionla and behavioral problems and educational attainment. Am Sociol Rev 69 (5):636-658

3. Barbaresi WJ, Katusic SK, Colligan RC, Weaver AL, Jacobsen SJ (2007) Long-term school outcomes for children with attention-deficit/hyperactivity disorder: a populationbased perspective. J Dev Behav Pediatr 28 (4):265-273. doi:10.1097/DBP.0b013e31811ff87d00004703-200708000-00001 [pii]

4. Fletcher JM (2008) Adolescent depression: diagnosis, treatment, and educational attainment. Health Econ 17 (11):1215-1235

5. Kessler RC, Foster CL, Saunders WB, Stang PE (1995) Social consequences of psychiatric disorders, I: Educational attainment. Am J Psychiatry 152 (7):1026-1032 6. Breslau J, Lane M, Sampson N, Kessler RC (2008) Mental disorders and subsequent educational attainment in a US national sample. J Psychiatr Res 42 (9):708-716 7. Laukkanen E, Shemeikka S, Notkola IL, Koivumaa-Honkanen H, Nissinen A (2002) Externalizing and internalizing problems at school as signs of health-damaging behaviour and incipient marginalization. Health Promot Int 17 (2):139-146 
8. Kessler RC, Amminger GP, Aguilar-Gaxiola S, Alonso J, Lee S, Ustun TB (2007) Age of onset of mental disorders: a review of recent literature. Curr Opin Psychiatry 20 (4):359-364. doi:10.1097/YCO.0b013e32816ebc8c

9. Merikangas KR, Nakamura EF, Kessler RC (2009) Epidemiology of mental disorders in children and adolescents. Dialogues Clin Neurosci 11 (1):7-20

10. Reef J, Diamantopoulou S, van Meurs I, Verhulst FC, van der Ende J (2011)

Developmental trajectories of child to adolescent externalizing behavior and adult DSMIV disorder: results of a 24-year longitudinal study. Soc Psychiatry Psychiatr Epidemiol 46(12):1233-41. doi:10.1007/s00127-010-0297-9

11. Jonsson U, Bohman H, von Knorring AL, Olsson G, Paaren A, von Knorring L (2011) Mental health outcome of long-term and episodic adolescent depression: 15-year follow-up of a community sample. J Affect Disord 130(3):395-404

doi:10.1016/j.jad.2010.10.046

12. Fergusson DM, Woodward LJ (2002) Mental health, educational, and social role outcomes of adolescents with depression. Arch Gen Psychiatry 59 (3):225-231

13. Stansfeld SA, Clark C, Rodgers B, Caldwell T, Power C (2011) Repeated exposure to socioeconomic disadvantage and health selection as life course pathways to mid-life depressive and anxiety disorders. Soc Psychiatry Psychiatr Epidemiol 46 (7):549-558. doi:10.1007/s00127-010-0221-3

14. Swedish National Agency for Education (2006) Equity trends in the Swedish school system. Stockholm

15. Bjorkenstam C, Weitoft GR, Hjern A, Nordstrom P, Hallqvist J, Ljung R (2011)

School grades, parental education and suicide--a national register-based cohort study. $\mathrm{J}$

Epidemiol Community Health. doi:jech.2010.117226 [pii]

10.1136/jech.2010.117226

16. Gunnell D, Lofving S, Gustafsson JE, Allebeck P (2011) School performance and risk of suicide in early adulthood: Follow-up of two national cohorts of Swedish schoolchildren. J Affect Disord. doi:S0165-0327(11)00017-6 [pii]

10.1016/j.jad.2011.01.002

17. Jablonska B, Lindberg L, Lindblad F, Rasmussen F, Ostberg V, Hjern A (2009)

School performance and hospital admissions due to self-inflicted injury: a Swedish national cohort study. Internat J Epidemiol 38 (5):1334-1341. doi:dyp236 [pii] 10.1093/ije/dyp236

18. Hout M, DiPrete TA (2006) What we have learned: RC28's contributions to knowledge about social stratification. Res Soc Strat Mob 24:1-20

19. Ross C, Wu C (1995) The links between education and health. Am J Sociol 60:719743

20. Cutler D, Lleras-Muney A (2006) Education and healt: evaluating theories and evidence. National Poverty Center Working Paper Series Washington DC: National Poverty Center

21. Freudenberg N, Ruglis J (2007) Reframing school dropout as a public health issue.

Prev Chronic Dis 4 (4):A107

22. Goodman A, Joyce R, Smith JP (2011) The long shadow cast by childhood physical and mental problems on adult life. Proc Natl Acad Sci U S A 108 (15):6032-6037.

doi:1016970108 [pii]

10.1073/pnas. 1016970108 
23. Miech RA, Caspi A, Moffitt TE, Wright BRE, Silva PA (1999) Low Socioeconomic Status and Mental Disorders: A Longitudinal Study of Selection and Causation During Young Adulthood. Am J Sociol 104 (4):1096-1131

24. Johnson JG, Cohen P, Dohrenwend BP, Link BG, Brook JS (1999) A longitudinal investigation of social causation and social selection processes involved in the association between socioeconomic status and psychiatric disorders. J Abnorm Psychol 108 (3):490499

25. Dohrenwend BP, Levav I, Shrout PE, Schwartz S, Naveh G, Link BG, Skodol AE, Stueve A (1992) Socioeconomic status and psychiatric disorders: the causation-selection issue. Science 255 (5047):946-952

26. Amone-P'Olak K, Burger H, Ormel J, Huisman M, Verhulst FC, Oldehinkel AJ (2009) Socioeconomic position and mental health problems in pre- and early-adolescents: the TRAILS study. Soc Psychiatry Psychiatr Epidemiol 44 (3):231-238.

doi:10.1007/s00127-008-0424-z

27. World Health Organization (1993) The ICD-10 Classification of Mental and Behavioural Disorders. Diagnostic Criteria for Research WHO, Geneva, Switzerland 28. Björklund A, Lindahl M, Sund K (2003) Family background and school performance during turbulent era of school reforms. Swedish Econ Policy Rev 10:111-136 29. van Buuren S, Boshuizen HC, Knook DL (1999) Multiple imputation of missing blood pressure covariates in survival analysis. Stat Med 18 (6):681-694

30. Eaton WW, Muntaner C, Bovasso G, Smith C (2001) Socioeconomic status and depressive syndrome: the role of inter- and intra-generational mobility, government assistance, and work environment. J Health Soc Behav 42 (3):277-294

31. Ritsher JE, Warner V, Johnson JG, Dohrenwend BP (2001) Inter-generational longitudinal study of social class and depression: a test of social causation and social selection models. Br J Psychiatry Suppl 40:s84-90

32. Ahren-Moonga J, Silverwood R, Klinteberg BA, Koupil I (2009) Association of higher parental and grandparental education and higher school grades with risk of hospitalization for eating disorders in females: the Uppsala birth cohort multigenerational study. Am J Epidemiol 170 (5):566-575. doi:kwp166 [pii]

10.1093/aje/kwp166

33. ten Have M, Oldehinkel A, Vollebergh W, Ormel J (2003) Does educational background explain inequalities in care service use for mental health problems in the Dutch general population? Acta Psychiatr Scand 107:178-187

34. Vanheusde K, van der Ende J, Mulder CL, van Lenthe FJ, Verhulst FC, Mackenbach JP (2008) The use of mental health services among young adults with emotional and behavioural problems: equal use for equal needs? Soc Psychiatry Psychiatr Epidemiol 43:808-815

35. Gudmundsdottir G, Vilhjalmsson R (2010) Group differences in outpatient helpseeking for psychological distress: Results from a national prospective study of Icelanders. Scand J Public Health 38:160-167

36. Hazel NA, Hammen C, Brennan PA, Najman J (2008) Early childhood adversity and adolescent depression: the mediating role of continued stress. Psychological Medicine 38 (4):581-589. doi:S0033291708002857 [pii]

$10.1017 / \mathrm{S} 0033291708002857$ 
37. McLaughlin KA, Conron KJ, Koenen KC, Gilman SE Childhood adversity, adult stressful life events, and risk of past-year psychiatric disorder: a test of the stress sensitization hypothesis in a population-based sample of adults. Psychol Med 40 (10):1647-1658. doi:S0033291709992121 [pii] 10.1017/S0033291709992121

38. Butterworth P, Leach LS, Pirkis J, Kelaher M (2011) Poor mental health influences risk and duration of unemployment: a prospective study. Soc Psychiatry Psychiatr Epidemiol. doi:10.1007/s00127-011-0409-1

39. Jonsson U, Bohman H, Hjern A, von Knorring L, Paaren A, Olsson G, von Knorring AL (2011) Intimate relationships and childbearing after adolescent depression: a population-based 15 year follow-up study. Soc Psychiatry Psychiatr Epidemiol 46(8):711-721. doi:10.1007/s00127-010-0238-7

40. Kendler KS, Gardner CO, Prescott CA (2002) Toward a comprehensive developmental model for major depression in women. Am J Psychiatry 159 (7):11331145

41. Kendler KS, Gardner CO, Prescott CA (2006) Toward a comprehensive developmental model for major depression in men. Am J Psychiatry 163 (1):115-124. doi: $163 / 1 / 115$ [pii]10.1176/appi.ajp.163.1.115

42. Kessler RC, Berglund P, Demler O, Jin R, Merikangas KR, Walters EE (2005)

Lifetime prevalence and age-of-onset distributions of DSM-IV disorders in the National Comorbidity Survey Replication. Arch Gen Psychiatry 62 (6):593-602

43. Pardini D, White HR, Stouthamer-Loeber M (2007) Early adolescent psychopathology as a predictor of alcohol use disorders by young adulthood. Drug Alcohol Depend 88 Suppl 1:S38-49. doi:S0376-8716(06)00485-6 [pii]10.1016/j.drugalcdep.2006.12.014

44. Kessler RC, Avenevoli S, Ries Merikangas K (2001) Mood disorders in children and adolescents: an epidemiologic perspective. Biol Psychiatry 49 (12):1002-1014. doi:S0006322301011295 [pii]

45. Green H, McGinnity A, Meltzer H, Ford T, Goodman R (2005) Mental health of children and young people in Great Britain. Palgrave MacMillan, 46. Ford T, Goodman R, Meltzer H (2003) The British Child and Adolescent Mental Health Survey 1999: the prevalence of DSM-IV disorders. J Am Acad Child Adolesc Psychiatry 42:1203-1211

47. Kessler RC, Berglund P, Demler O, Jin R, Koretz D, Merikangas KR, Rush AJ, Walters EE, Wang PS (2003) The epidemiology of major depressive disorder: results from the National Comorbidity Survey Replication (NCS-R). JAMA 289 (23):30953105. doi:10.1001/jama.289.23.3095289/23/3095 [pii]

48. Nock MK, Hwang I, Sampson NA, Kessler RC (2010) Mental disorders, comorbidity and suicidal behavior: results from the National Comorbidity Survey Replication. Mol Psychiatry 15 (8):868-876. doi:mp200929 [pii]10.1038/mp.2009.29 


\section{$\underline{\text { Appendix }}$}

Adjusted hazards ratiosf or effects of grades, stratified by period

\begin{tabular}{|c|c|c|c|c|c|c|c|}
\hline & \multirow[b]{2}{*}{ Grade } & \multicolumn{2}{|l|}{ All depression } & \multicolumn{2}{|c|}{ Dep without externalising } & \multicolumn{2}{|c|}{ Dep with externalising } \\
\hline & & $\begin{array}{l}\text { Old grading } \\
\text { system }\end{array}$ & $\begin{array}{l}\text { New grading } \\
\text { system }\end{array}$ & $\begin{array}{l}\text { Old grading } \\
\text { system }\end{array}$ & $\begin{array}{l}\text { New grading } \\
\text { system }\end{array}$ & $\begin{array}{l}\text { Old grading } \\
\text { system }\end{array}$ & $\begin{array}{l}\text { New grading } \\
\text { system }\end{array}$ \\
\hline Adolescent & $\begin{array}{l}\text { High/Average } \\
\text { grades } \\
\text { Low/ v. Low grades }\end{array}$ & $\begin{array}{l}1 * * \\
10.6(2.4,46.6)\end{array}$ & $\begin{array}{l}1 * * * \\
6.5(2.3,18.2)\end{array}$ & $\begin{array}{l}1 * \\
5.5(1.1,26.5) \\
\end{array}$ & $\begin{array}{l}1 * \\
4.1(1.2,13.8)\end{array}$ & $\begin{array}{l}1 * * * \\
71.6(4.0,1289.0)\end{array}$ & [no cases] \\
\hline Adult & $\begin{array}{l}\text { High/Average } \\
\text { grades } \\
\text { Low/ v. Low grades }\end{array}$ & $\begin{array}{l}1 \\
6.2(0.7,53.2)\end{array}$ & $\begin{array}{l}1 * \\
2.2(1.1,4.5)\end{array}$ & $\begin{array}{l}1 \\
5.4(0.3,99.8)\end{array}$ & $\begin{array}{l}1 \\
1.3(0.5,3.8)\end{array}$ & $\begin{array}{l}1 \\
8.0(0.4,171.6)\end{array}$ & $\begin{array}{l}1 * * \\
4.5(1.6,13.1)\end{array}$ \\
\hline
\end{tabular}

High/Average grades are above average to $1 \mathrm{SD}$ below average; Low/v.low grades are $>1$ SD below average 